\title{
Yol Güvenliğinin Artırılmasında Kaza Kara Noktaları Tespitinin Önemi
}

\author{
${ }^{1}$ Hasan Bozkurt ${ }^{* 2}$ Havanur Yilmaz \\ ${ }^{1}$ Bilecik Şeyh Edebali Üniversitesi, Mühendislik Fakültesi, İnşaat Mühendisliği Bölümü, Türkiye \\ *22Lisansüstü Eğitim Enstitüsü, İnşaat Mühendisliği Bölümü, Bilecik Şeyh Edebali \\ Üniversitesi, Türkiye
}

\begin{abstract}
Özet
Trafikte güvenlik kavramı trafik kazalarının meydana getirdiği kayıplar sonucunda dünyada ve ülkemizde önem kazanmıştır. Yol güvenlik projelerinin maliyetli olması nedeniyle trafik kazalar sonucunda oluşan kayıpların azaltılması için daha ekonomik ve kullanışlı yöntemlere ihtiyaç duyulmuştur. Bu yöntemlerin en yaygın olanı kaza kara noktalarının belirlenmesidir. Meydana gelen her kazanın yerinin harita üzerinde işaretlenerek en çok işaretleme yapılan yerin kara nokta olarak tespit edilmesi kara nokta belirleme yöntemini oluşturmaktadır. Bu yöntemle kazaların yüksek oranda meydana geldiği yol kesimleri ve kavşak noktaları incelenerek tehlikeli olarak görülen kaza kara noktaları tespit edilmektedir. Bu değerlendirme çalışmasının amacı kaza kara noktalarını meydana getiren durumları ve kara noktaların yaygın olarak görüldüğü yerleri belirlemektir. Daha önce yapılan çalışmalar ışı̆̆ında kara noktaların nasıl tespit edileceği ve bu kritik noktaların tespitinde kullanılan geleneksel metotları incelemek amaçlanmıştır. Çalışma sonucunda karayolu güvenliğinin sağlanmasında kara noktaların tespit edilerek gerekli iyileştirmelerin yapılması gerektiği ve bu șekilde meydana gelebilecek kaza oranlarının azaltılarak trafik güvenliğinin artırılabileceği belirtilmiştir.
\end{abstract}

Anahtar Kelimeler: Kara nokta, yol güvenliği, trafik kazaları

\begin{abstract}
The concept of safety in traffic has gained importance in the world and in our country as a result of the losses caused by traffic accidents. Due to the high cost of road safety projects, more economical and useful methods were needed to reduce the losses caused by traffic accidents. The most common of these methods is the determination of accident black spots. Marking the place of each accident on the map and determining the most marked place as a black spot constitutes the black spot determination method. With this method, road sections and junction points where accidents occur at a high rate are examined and accident black spots that are considered dangerous are determined. The purpose of this assessment study is to determine the situations that cause accident black spots and the places where black spots are common. In the light of the previous studies, it is aimed to examine how to detect black spots and to examine the traditional methods used in the detection of these critical points. As a result of the study, it was stated that black spots should be detected and necessary improvements should be made in ensuring road safety and traffic safety can be increased by reducing the accident rates that may occur in this way.
\end{abstract}

Keywords: Black spot, road safety, traffic accidents

\footnotetext{
* Sorumlu Yazar: Adres: Lisansüstü Eğitim Enstitüsü, İnşaat Mühendisliği Bölümü, Bilecik Şeyh Edebali Üniversitesi, Bilecik TÜRKIYE. E-mail adresi: hava.nury95@gmail.com, Telefon: 05358946080
} 


\section{Giriş}

Trafik kazalarının meydana getirdiği maddi ve manevi kayıplar insan yaşamını, kaza sonrasında oluşan hasarlar ülke ekonomisini olumsuz yönde etkilemektedir. Bu durum dünyada ve ülkemizde trafik güvenliği kavramının önem kazanmasına sebep olmuştur. Trafik güvenliğinin sağlanmasındaki ana unsur kazaları azaltmaktır. Trafik kazalarının azaltılması için yapılan çalışmalarda öncelikle kazayı meydana getiren nedenler belirlenerek bu nedenler doğrultusunda önlemler alınmaktadır [1]. Kazanın ne zaman ve nerede meydana geleceği bilinemez fakat kazaya etki eden insan, taşıt, yol gibi birçok faktör göz önüne alınarak bunlara yönelik önlemler alınabilir. Yol ve kavşak tasarımının standartlara uygun yapılması, sürücü ve yayaların bilinçlendirilmesi, trafik ihlallerinin önüne geçilmesi için yasal düzenlemelerin yapılması ve uygulanması, kaza sonrası müdahalenin gecikmemesi gibi başlıca önlemler alınmalıdır [2]. Yol güvenliğini artırmak ve kazaları azaltmak için yapılan çalışmalar doğrultusunda kara noktaların tespit edilmesi en yaygın yöntemlerden biridir. Trafik kazalarının gerçekleştiği bölgeler tespit edilip incelenerek kazanın sıklıkla meydana geldiği kaza kara noktaları belirlenerek bu nokta üzerinde iyileştirme çalışmaları yapılmaktadır. Yolun belirli bir noktası veya kesiminde belirli bir zaman aralığında belirli bir sayı üzerinde kaza oluştuğu gözlemlenen yerler kara nokta olarak adlandırılmaktadır [3]. Kaza analizine kara nokta olarak isimlendirilen bölgeler belirlenerek başlanır. Yoğun olarak kazaların meydana geldiği bu noktalarda bölgenin fiziksel özellikleri, kazanın meydana geliş şekli gibi kaza ile ilgili veriler toplanmaktadır. Toplanan veriler doğrultusunda yapılacak kaza analizleri ile problemlerin çözümü ve trafik güvenliğinin sağlanmasına yönelik çalışmalar yapılmaktadır [4].

$\mathrm{Bu}$ değerlendirme çalışmasının amacı literatürde yer alan çalışmalar ışığında kaza kara noktalarının yaygın olarak görüldüğ̈ yerleri, kara noktaları meydana getiren durumları ve kara nokta tespitinde kullanılan metotları derleyerek trafik güvenliği konusunda kara noktaların önemini göstermektir. Kara noktaların yaygın olarak görüldüğü yerlerde hangi sebeplerin risk oluşturduğu ve bu durumlarda ne yapılması gerektiği irdelenmiştir. Kara nokta olarak adlandırılan kritik noktaların tespit edilmesinde kullanılan metotlar incelenerek coğrafi bilgi sistemleri yardımı ile kara nokta analizinde verilerin doğru ve detaylı incelenmesinin mümkün olacağından bahsedilmiştir. Ayrıca trafik güvenliği konusu ülkemiz için son derece önemli iken yapılan çalışmaların azlığı da ortadadır. Çalışmamızda sıkça kara noktaların tespit edilmesiyle trafik kazalarındaki kayıpların azaltılabileceği vurgulanarak trafik güvenliğine yönelik çalışmaların önem kazanması ve trafikte güvenliğin artırılması hedeflenmektedir.

\section{Kaza Kara Noktalarını Meydana Getiren Durumlar}

Kazanın gerçekleştiği yerin kara nokta olarak adlandırılabilmesi için o bölgede meydana gelen kaza miktarı gibi belirleyici parametrelere sahip olması gerekmektedir. Yolun belli bir kesiminde gerçekleşen kaza sayısının geçen taşıt miktarına oranlanması ile kaza miktarı hesaplanmaktadır. Belirli bir bölge veya noktanın kaza kara noktası olarak belirlenmesi için belirli bir kaza türünün ağırlıklı olarak gerçekleşmesi veya aynı bölgede bir yıl içerisinde en az 4 kere kaza yaşanmış olması gerekmektedir. Yolun o kesiminde veya noktasında farklı kaza türleri gerçekleşmiş ve kazalar belirli bir türde yoğunlaşmamışsa kaza kara noktası olarak tanımlanamaz [5].

Kara noktalarının belirlenmesi için kaza kayıtlarından yararlanılmaktadır fakat bazı noktaların 
bu şekilde belirlenmesi yeterli ve ayırt edici olmayabilir. Bu gibi noktalarda arazi gözlemi yapılarak yol bilgileri incelenmelidir ve güvenlik olarak sorun oluşturduğu tespit edilirse güvenlik sorunlu yerler listesi oluşturulmalıdır [6]. Sürücülerin en çok problem yaşadığ1 hatalara sebebiyet veren yerler olan kaza kara noktalarında meydana gelen kazalar sonucunda maddi manevi kayıpların yaşanmaması için oldukça dikkatli olunmalıdır.

Kaza kara noktalarının en yaygın görüldüğ̈̈ yerler:

- Eşdüzey kavşaklar

- Yerleşim bölgelerinin geçişleri

- Akaryakıt tesislerinin giriş ve çıkışları

- Trafik İşaretlerinin yetersiz olduğu yerler

- Şehir içi aydınlatma yetersizliği olan yerler

- Standartlara uymayan hatalı yollar [5]

Trafikte yaşanan problemlerin ve trafik kazalarının yoğun olarak görüldüğü taşıtların kesişim noktası olan kavşaklar karayollarının kaza noktalarındandır. Yapılan çalışmaların sonuçlarına göre kazaların büyük oranda gerçekleştiği kavşak noktaları potansiyel olarak kazanın meydana gelme ihtimalinin yüksek olduğu kesimlerdir. Kavşakların tasarım ve uygulamasında yapılan hatalar ciddi kayıplara neden olmaktadır. Yol ve kavşak güvenliğini sağlamak geometrik elemanların doğru ve gerekli boyutlarda tasarlanmasıyla mümkündür. Ayrıca kavşakların görüşün kısıtlı olacağı düşey ve yatay kurp içerisinde yer almayacak şekilde yapılması daha güvenli olacaktır.

Yerleşim bölgelerinde gerçekleşen kazaların çoğu transit geçişin kullanıldığ1 şehirlerarası yollarda ve yerleşim yerlerinin giriş çıkışlarında yoğun olarak meydana gelmektedir. $\mathrm{Bu}$ duruma yol güzergâhı boyunca sistemsiz bir yapılanmanın oluşu sebebiyet vermektedir. İmar planlamasından yoksun yapılanmanın neden olduğu düzensizlik şehirlerarası yolları birçok noktasından giriş çıkışın gerçekleşebileceği şehir içi yol haline getirerek kaza noktası olmasina sebebiyet vermektedir [5].

Karayollarında kaza noktası olarak görülen bir başka yer de yol kenarlarındaki akaryakıt istasyonları ve diğer tesislerin bulunduğu noktalardır. Bu noktaların kaza noktası potansiyeli taşıması giriş ve çıkışlarının elverişli olmayışı, görüş mesafesinin yetersiz oluşu gibi yanlış tasarım ve konumlandırmadan kaynaklanmaktadır. Bu tür kaza noktalarında yaşanan problemlerin trafik yönetmeliklerine uygun doğru tasarımın yapılması ile önüne geçilecektir [5].

\section{Kaza Kara Noktalarının Tespitinde Kullanılan Yöntemler}

Kaza kara noktalarının tanımlanmasında iki ayrı yaklaşım kullanılır. Bu yaklaşımlar:

1. Reaktif Yaklaşım: Trafik kazası meydana geldikten sonra elde edilen veriler doğrultusunda yapılan analizlere dayalı kara nokta tespit edilmesidir [7]. 
2.Proaktif Yaklaşım: Trafik kazası gerçekleşmeden önce kaza oluşumuna sebebiyet verecek tüm etkenleri kaza öncesinde değerlendirerek kaza oluşumunun yüksek görüldüğg̈ yerlerin tespit edilmesidir [7].

Çalışmada reaktif yaklaşıma bağlı geleneksel kaza kara noktası belirleme yöntemleri ele alınmıştır. Kaza kara noktalarının belirlenmesinde kullanılan yöntemler aşağıdaki gibidir:

- Kaza Sayısı Yöntemi

- Kaza Tekrar Oranı Yöntemi

- Tablo Yöntemi

- Eş Değer Ağırlık Yöntemi

- Oran Kalite Kontrolü Yöntemi

\subsection{Kaza Sayısı Yöntemi}

$\mathrm{Bu}$ yöntemle yapılan kaza analizi belirli bir zamanda belirli bir noktada gerçekleşen kaza sayısının hesaplanmasına dayanır [8]. Belirlenen bölgeden hesaplanan kaza sayısı belirli bir eşik değerini geçiyorsa kara nokta tanımlaması yapılabilir. Bu belirli eşik değeri bir yılda gerçekleşen beş ya da daha fazla kaza sayısı alınabileceği gibi ilgili otoriteye, isteğe ve bütçeye bağlıdır. Kritik sayı belirleme tekniğinin belirsizliği nedeniyle yöntem basit ve yaniltıcidir [9].

Ayrıca aynı sayıda kazanın gerçekleştiği iki noktayı ele alacak olursak ve bir noktanın trafik hacmi diğerinden fazla ise aynı tehlike potansiyeli taşıdıklarını söylemek doğru olmaz. Bu yüzden yöntemde YOGT değeri önemli bir rol oynamaktadır. Kritik değer için ülkemizde genel bir kabul bulunmamaktadır. Bu nedenle yapılan bazı çalışmalarda YOGT değeri 2000 araç/gün' den az olması halinde kritik kaza sayısının 3, 2000 araç/gün olan yol kesimlerinde 5 olarak seçilebileceği uygun görülmüştür [8]. Kritik değer belirsizliği, trafik yoğunluğunun dikkate alınmaması gibi dezavantajları bulunduğu için çoğu zaman yanıltıcı olan bu yöntemin kullanımı trafik yoğunluğunun ve yıllık kaza sayısının az olduğu yollarda sınırlı kalmaktadır [8].

\subsection{Kaza Tekrar Oranı Yöntemi}

Kaza tekrar oranı yöntemi kaza sayısı yöntemine kıyasla trafik hacminin hesaba katılması nedeniyle daha güvenilir sonuçlar almayı sağlamaktadır. Kara noktanın bulunması için kullanılan kaza oranı denklemi aşağıdaki formülle bulunmaktadır.

$\mathrm{R}_{\mathrm{sp}}=\left(\mathrm{A} \cdot 10^{6}\right) /(365 . \mathrm{T} . \mathrm{V})$

Denklemdeki:

$\mathrm{R}_{\mathrm{sp}}=$ Kaza tekrar oran 1

$\mathrm{A}=$ Belirlenen alanda gerçekleşen yıllık kaza sayısı

$\mathrm{T}=$ Periyot süresi

V = Kaza analizi süresince yıllık ortalama günlük trafik ( Kavşak noktaları için bütün kavşak kollarının toplam hacmi ) [6]

Çalışma daha uzun bir bölgede gerçekleştirilecekse kaza tekrar oranı denklemi: 
$\mathrm{R}_{\mathrm{se}}=\left(\mathrm{A} \cdot 10^{6}\right) /(365 \cdot \mathrm{T} \cdot \mathrm{V} . \mathrm{L})$

$\mathrm{L}=$ Kaza oranı belirlenen kesimin uzunluğu ( $\mathrm{km}$ cinsinden )

Kaza oranı denkleminden elde edilen değerin önceden ölçüt olarak belirlenen değerden fazla olması durumunda analiz yapılan yer kaza kara noktası olarak nitelendirilmektedir.

\subsection{Tablo Yöntemi}

Tablo yöntemi matris yöntemi veya sayı-oran yöntemi olarak da bilinmektedir. Bu yöntem kaza sayısı yöntemi ve kaza tekrar oranı yönteminin birlikte kullanılarak bir tablo oluşturulması esasına dayanmaktadır. Kaza noktalarına numaralar verilerek her kesimin kaza sayıs1 ve tekrar oranı belirlendikten sonra tekrar sayıları satırlara, kaza oran sayıları sütunlara yazılarak tablo haline getirilir. Tablonun her hücresine tekrar sayılarına göre gruplandırma yapılarak tablo doldurulur. Tablonun en alt sağ hücresine denk gelen yer kazanın en fazla tekrarlandığı kesimi göstereceği için kara nokta olarak nitelendirilir [5, 8].

$\mathrm{Bu}$ yöntemin uygulandiğı tablo örneği aşağıda gösterilmiştir. Tablonun sağ en alt köşesinde yer alan J8, G65, U82 olarak adlandırılan kesimler kaza tekrarı ve kaza tekrar oranlarının en fazla gözlemlendiği kesimler olduğu için tehlike oranı diğer kesimlerden fazladır. [8]. ( Tablo 3.1 )

Tablo 3.1. Tablo yöntemiyle kara nokta tespitine ait bir örnek [8]

\begin{tabular}{|c|c|c|c|c|c|c|c|}
\hline $\begin{array}{c}\text { Kaza } \\
\text { Tekrarı }\end{array}$ & \multicolumn{7}{|c|}{ Kaza Tekrarı Oranı } \\
\hline & $\mathbf{0 - 6}$ & $\mathbf{6 - 1 2}$ & $\mathbf{1 2 - 1 8}$ & $\mathbf{1 8 - 2 4}$ & $\mathbf{3 4 - 3 6}$ & $\mathbf{3 6 - 4 2}$ & $\mathbf{4 2 -}$ \\
\hline $\mathbf{0 - 3}$ & A5.C7 & H1.Y7 & S3 & B6.N1 & D5.E8 & R1.T1.P2 & Z6.E9 \\
\hline $\mathbf{3 - 5}$ & F57 & J65 & I87 & L2 & L2.S3 & A4.B43 & C 2. K60 \\
\hline $\mathbf{5 - 8}$ & 0 & G5 & K1.M7 & O3.X3 & A1.B3,C5,X7 & D23.G6 & S55,U4,G98 \\
\hline $\mathbf{8 - 1 0}$ & 0 & 0 & 0 & A21.G7 & 0 & S65.A9,U5 & 0 \\
\hline $\mathbf{1 0 - 1 5}$ & 0 & 0 & 0 & W6.W8 & R11 & G9.H11 & J8,G65, U82 \\
\hline
\end{tabular}

\subsection{Kaza Şiddeti Yöntemi (Eş Değer Ă̆grlık Yöntemi)}

Bu yöntem diğer yöntemlerden farklı olarak kazada ölenlerin, yaralananların ve kazada hasar gören araçların dikkate alınarak ölen ve yaralanan kişiler için belirli bir katsayı göz önüne alınarak ağırlık şiddetinin hesaplanmasına dayanmaktadır. Bir ölümlü kaza 9 hasarlı kazaya, bir yaralanmalı kaza 3 maddi hasarlı kazaya eş değer kabulü yapılarak kaza şiddeti hesaplanmaktadır [8]. Kaza şiddeti yönteminde kullanılan denklem aşağıdaki gibidir.

$\mathrm{S}=(9 \cdot \mathrm{F})+(3 . \mathrm{I})+\mathrm{P}$

S: Kaza şiddeti

F:Ölümlü kaza sayısı

I:Yaralanmalı kaza sayıs1

P: Maddi hasarlı kaza sayısı

\subsection{Oran Kalite Kontrolü Yöntemi}


Kaza sayısı, kaza tekrar oranı ve kaza şiddeti yöntemlerinin de içinde bulunduğu daha kapsamlı ve istatistiksel bir yöntemdir. Karayolları genel müdürlüğü tarafindan 1994 yılından beri kullanılan bu yöntem kaza verilerinin istatistiksel değerlendirilmesi yapıldıktan sonra ülke genelindeki kritik noktaların belirlenmesinde kullanılır. Kritik değer hesabında güven aralığını k sabiti belirlemektedir [5]. Belirlenen her nokta veya kesim için önce indeks değerleri hesaplanır. Kaza kesiminin kara nokta olarak adlandırılabilmesi için indeks değerlerinin her biri 1'den büyük olmalıdır [7]. Bahsedilen indeks değerleri:

- Kaza oranı indeksi

- Frekans indeksi

- Şiddet İndeksi

Kaza oranı indeks değeri (RI) aşağıdaki gibi hesaplanmaktadır.

$\mathrm{RI}=\mathrm{R}_{\mathrm{i}} / \mathrm{R}_{\mathrm{c}}$

$\mathrm{R}_{\mathrm{i}}$ : i kesimi için kaza oranı

$\mathrm{R}_{\mathrm{c}}$ : kritik kaza oranı

Frekans indeks değeri (FI) aşağıdaki gibi hesaplanmaktadır.

$\mathrm{FI}=\mathrm{F}_{\mathrm{i}} / \mathrm{F}_{\mathrm{c}}$

$\mathrm{F}_{\mathrm{i}}$ : i kesimi için kaza frekansı

$F_{c}$ : kritik kaza frekansı

Şiddet indeks değeri (SI) aşağıdaki gibi hesaplanmaktadır.

$\mathrm{SI}=\mathrm{S}_{\mathrm{i}} / \mathrm{S}_{\mathrm{c}}$

$\mathrm{S}_{\mathrm{i}: \mathrm{i}}$ kesimi için kaza şiddeti

$\mathrm{S}_{\mathrm{c}}$ : kritik kaza şiddeti

Yukarıdaki denklemlerde bulunan kritik kaza oranı $\left(\mathrm{R}_{\mathrm{c}}\right)$, kritik kaza frekansı $\left(\mathrm{F}_{\mathrm{c}}\right)$, kritik kaza şiddeti $\left(S_{c}\right)$ gibi kritik değerler de aşağıdaki denklemler aracılığıyla hesaplanır.

$\mathrm{R}_{\mathrm{c}}=\mathrm{R}_{\mathrm{i}}+\mathrm{K} \sqrt{\mathrm{R}_{\mathrm{i}} / \mathrm{M}_{\text {ort }}}+0.5 / \mathrm{M}_{\text {ort }}$

$\mathrm{R}_{\mathrm{c}}$ : kritik kaza oranı

$\mathrm{R}_{\mathrm{i}}$ : i kesimi için kaza oranı

K: sabit

M: Etüt süresince ortalama milyon-araç-km

$F_{c}=F_{i}+K \sqrt{F_{i} / M_{o r t}}+0.5 / M_{o r t}$ 
$F_{c}$ : kritik kaza frekansı

$\mathrm{F}_{\mathrm{i}}$ : i kesimi için kaza frekansı

K: sabit

M: Etüt süresince ortalama milyon-araç-km

$\mathrm{S}_{\mathrm{c}}=\mathrm{S}_{\mathrm{i}+} \mathrm{K} \sqrt{\mathrm{S}_{\mathrm{i}} / \mathrm{M}_{\mathrm{ort}}}+0.5 / \mathrm{M}_{\text {ort }}$

$\mathrm{S}_{\mathrm{c}}$ : kritik kaza frekans1

$\mathrm{S}_{\mathrm{i}}$ : i kesimi için kaza frekansı

K: sabit

M: Etüt süresince ortalama milyon-araç-km

İndeks değerleri bulunurken güvenirlik seviyesine göre seçilecek olan k sabiti aşağıdaki tabloda verilmiştir [7, 10]. (Tablo 3.2)

Tablo 3.2. Emniyet seviyesine bağlı k değerleri [10]

\begin{tabular}{|c|c|}
\hline Emniyet Seviyesi & K Değerleri \\
\hline 0.995 & 2.576 \\
\hline 0.95 & 1.645 \\
\hline 0.90 & 1.282 \\
\hline
\end{tabular}

$\mathrm{Bu}$ yönteme göre belirlenen noktanın kara nokta olarak tanımlanabilmesi için denklemlerde hesaplanan kaza oranı indeks değerinin (RI), frekans indeks değerinin (FI) ve şiddet indeks değerinin (SI) 1'den büyük olması gerekmektedir [7].

\section{Coğrafi Bilgi Sistemlerinin Kara Nokta Analizinde Kullanımı}

Coğrafi Bilgi Sistemi (CBS) veriyi saklama, geri çağırma; haritalar raporlar ve planlar üzerinden veri raporu oluşturma; veriyi modelleme ve analiz etme gibi birçok seçeneği içinde barındıran bir sistemdir. Ulaştırma mühendisliği alanında bu sistemden trafik kazalarının analizinde, kavşakların kontrol edilmesinde, ulaşım planlanması ve yönetiminde faydalanılmaktadır. Trafik kazalarını meydana getiren sebeplerin belirlenebilmesi için kazaya ait kaza tarih ve saati, kazanın gerçekleştiği yol tipi, meydana gelme şekli, ölü ve yaralı sayısı, hasar tespiti gibi birçok bilginin detaylıca ele alınması gerekmektedir.

Coğrafi Bilgi Sistemlerine ait yazılımlar kara noktaların belirlenmesine ve gereken önlemlerin alınmasına fayda sağlamaktadır. Kazaların gerçekleştiği yerlerin, meydana geldiği zamanın, kaza tipinin analizler sonucunda karar vericiler yardımıyla kaza tekrarı yaşanan yerlerin tespiti ve zamansal analizlerinin yapılmasına olanak tanımaktadır [11]. Ayrıca CBS kara nokta haritalarının oluşturulmasını ve trafik kazaları karar sisteminde ara yüzler oluşturarak veri tabanı oluşturmayı sağlamaktadır $[11,12]$. 


\section{Sonuç}

Çalışmada kaza kara noktasını meydana getiren durumlardan bahsedilmiştir. Bir yerin kara nokta olarak adlandırılması için o bölgede meydana gelen kaza miktarı gibi belirleyici parametrelere sahip olması gerekmektedir. Sürücülerin en çok problem yaşadığ 1 kritik noktaların en yaygın olarak görüldügü yerlerden bahsedilmiştir. Eşdüzey kavşaklar, yerleşim bölgelerinin geçişleri, akaryakıt tesislerinin giriş ve çıkışları, trafik İşaretlerinin yetersiz olduğu yerler ve şehir içi aydınlatma yetersizliği olan yerlerin kara noktaların genel olarak görüldüğü kesimler olduğu üzerine durularak bu bölgelerde alınabilecek önlemlerden bahsedilmiştir.

Kaza kara noktalarının tespitinde kullanılan metotlar üzerinde durulmuştur. Kaza sayısı metodu diğerlerine göre daha basit bir yöntemdir fakat kritik nokta seçiminde ülkemizde herhangi bir genel kabulün olmayışı, seçimin yetkili kişilere ve isteğe bağlı değişebilmesi yöntemi yanıltıcı kılmaktadır. Ayrıca trafik yoğunluğunun hesaba katılmaması da diğer yöntemlere göre dezavantaj oluşturmaktadır. Bu yöntemin trafik yoğunluğunun az olduğu yollarda kullanımının sınırlı kalması daha doğru olacaktır. Kaza tekrar oranı yöntemi kaza sayısı yöntemine kıyasla trafik hacminin hesaba katılması nedeniyle daha güvenilir sonuçlar almayı sağlamaktadır. Tablo yönteminde ise kaza sayısı ve kaza tekrar oranı kullanılarak oluşturulan tablo aracılığıyla en tehlikeli noktanın belirlenmesi sağlanmaktadır. Diğer iki yöntemin bir arada kullanıldığı bu yöntemde riskli görülen kara nokta güvenilir şekilde bulunabilir. Eşdeğer ağırlık yöntemi diğer yöntemlerden kaza yapan araç ve kazazedelerin değerlendirilmesi yönüyle ayrılmaktadır. Kaza sonucu yaralanan, ölen kişi sayısı ve hasar gören araçlar ortak bir birimde toplanarak hesaplama yapılır. Oran kalite kontrol yöntemi KGM tarafindan da kullanılan kara nokta tespit yöntemidir. Diğer yöntemlerle kıyaslandığında kara nokta tespitinde fazladan mühendislik tecrübesi ve yorumu gerektirmeden denklemler ve kritik değerler aracılığıyla sonuca daha çabuk ulaştıran bir yöntemdir.CBS sistemlerinin kara nokta analizinde kullanılarak kaza tekrarı yaşanan yerlerin tespiti ve zamansal analizlerinin yapılmasına olanak tanıdığından, kara noktaların belirlenerek gereken önlemlerin alınmasına fayda sağladığından bahsedilmiştir. Yapılan çalışma ile trafikte kazaları azaltmak ve trafik güvenliğini artırmak için kara nokta olarak adlandırılan tehlike potansiyeli yüksek kesimlerin tespit edilerek yaşanan kazalar sonucu oluşan kayıp ve hasarların azaltılabileceği gösterilmiştir. Kaza kara noktalarının oluşumuna sebebiyet veren durumlar ve bunların oluşum sebepleri irdelenerek kara nokta tespitinde kullanılan başlıca yöntemler üzerinde durulmuştur.

Ülkemizde trafik kazası sonucu birçok insan yaşamını kaybetmekte, aileler dağılmakta ve bazı insanlar kaza sonucu hayatına engelli olarak devam etmek zorunda kalmaktadır. Yaşanan kayıplar insan psikolojisini derinden etkilerken meydana gelen hasarlarda ülke ekonomisine zarar vermektedir. Çalışmada bahsedilen kara noktaların tespit edilerek gerekli önlem ve iyileştirmelerin yapılmasıyla yaşanan olumsuzlukları azaltmanın mümkün olacağı gösterilmiştir. Tüm bunlarla birlikte toplumumuzun trafik güvenliği konusunda bilinçlendirilmesi, trafikte aktif veya pasif rol alan herkesin eğitilerek yapılacak en ufak hatanın büyük kayıplara yol açacağı, tüm bunların önüne alınan tedbirler ile geçilebileceğinin aşılanması da kazaların azaltılmasında büyük rol oynayacaktır. 
[1] Geymen, A., Dedeoğlu, O.K. (2016). Coğrafi Bilgi Sistemlerinden Yararlanılarak Trafik Kazalarının Azaltılması: Kahramanmaraş İli Örneği, Iğdır Üniversitesi Fen Bilimleri Dergisi, 79-88.

[2] Murat, Y.Ş., Şekerler, A. (2009) Trafik Kaza Verilerinin Kümelenme Analizi Yöntemi ile Modellenmesi, IMO Teknik Dergisi, 4759-4777.

[3] Tuncuk, M., Karaşahin, M. Coğrafi Bilgi Sistemleriyle Şehir içi Trafik Kaza Analizi: Isparta Örneği, http://www.imo.org.tr/resimler/ekutuphane/pdf/10164.pdf, (24.08.2020).

[4] Saplıŏglu, M., Karaşahin, M. (2005) Coğrafi Bilgi Sistemi Yardımı ile Isparta ili Kent içi Trafik Kaza Analizi, Mühendislik Bilimleri Dergisi, 321-332.

[5] Zambak, M. (2006). Konya Şehir Merkezindeki Kaza Kara Noktalarının Analizi, Yüksek Lisans Tezi, Selçuk Üniversitesi, Fen Bilimleri Enstitüsü / Otomotiv Anabilim Dal1, Konya.

[6] Yüksel, S. (2003) . Türkiye'de Kent içi Karayolu Güvenliği Üzerine Bir Araştırma, Yüksek Lisans Tezi, Balıkesir Üniversitesi, Fen Bilimleri Enstitüsü/İnşaat Mühendisliği Anabilim Dalı, Balıkesir.

[7] Açar, F. (2019). Trafik Kaza Kara Noktalarının Tespiti ve Çözüm Önerileri: Şırnak Örneği, Yüksek Lisans Tezi, Şırnak Üniversitesi, Fen Bilimleri Enstitüsü/İnşaat Mühendisliği Anabilim Dalı, Şırnak.

[8] Kahramangil, M., Şenkal, Ş. (1999). Kaza Kara Noktaları Belirleme Yöntemleri, II. Ulaşım Kongresi, 119-127.

[9] Arslan, V. (2001). Kaza Kara Noktalarının Belirlenmesinde ve Çözümlenmesinde Coğrafi Bilgi Sisteminin Kullanılması, Yüksek Lisans Tezi, Fen Bilimleri Enstitüsü, Ankara.

[10] Tunç, A. (2004). Yol güvenlik mühendisliği ve uygulamaları: Asil Yayın Dağıtım, $153-170$.

[11] Dektaş, R.O. (2018). Resmi Tatil Dönemlerinde Meydana Gelen Trafik Kaza Kara Noktalarının İrdelenmesi, Yüksek Lisans Tezi, Afyon Kocatepe Üniversitesi, Fen Bilimleri Enstitüsü/Harita Mühendisliği Anabilim Dalı, Afyon.

[12] Terzi, S., Karaşahin, M. (2002). Ulaştırma Mühendisliğinde CBS kullanımı, GAP 4. Mühendislik Kongresi Bildiriler Kitabı, Şanlıurfa. 